\author{
Abstracta Iranica \\ Abstracta Iranica Revue bibliographique pour le domaine irano-aryen \\ Volume 34-35-36 | 2017 \\ Comptes rendus des publications de 2011-2013
}

\title{
Nacim Pak-Shiraz. Shi'i Islam and Iranian Cinema. Religion and Spirituality in Film
}

\section{Agnès Devictor}

\section{(2) OpenEdition}

Journals

Édition électronique

URL : http://journals.openedition.org/abstractairanica/42405

DOI : 10.4000/abstractairanica.42405

ISSN : 1961-960X

Éditeur :

CNRS (UMR 7528 Mondes iraniens et indiens), Éditions de l'IFRI

Référence électronique

Agnès Devictor, « Nacim Pak-Shiraz. Shi' Islam and Iranian Cinema. Religion and Spirituality in Film », Abstracta Iranica [En ligne], Volume 34-35-36 | 2017, document 1, mis en ligne le 30 juillet 2017, consulté le 02 octobre 2020. URL : http://journals.openedition.org/abstractairanica/42405; DOI https://doi.org/10.4000/abstractairanica.42405

Ce document a été généré automatiquement le 2 octobre 2020.

Tous droits réservés 


\title{
Nacim Pak-Shiraz. Shi'i Islam and Iranian Cinema. Religion and Spirituality in Film
}

\author{
Agnès Devictor
}

\section{RÉFÉRENCE}

Nacim Pak-Shiraz. Shi'i Islam and Iranian Cinema. Religion and Spirituality in Film. LondonNew York, I.B. Tauris, 2011, 288 p. (International Library of Cultural Studies, Book 17)

1 Ce livre, au sujet très original, met en relation le cinéma, et plus particulièrement les films réalisés ces vingt dernières années en République islamique, avec le shi'isme tel qu'il est pratiqué, pensé et vécu en Iran.

2 L'A. commence par présenter le contexte dans lequel le shi'isme s'est développé, mettant en évidence le rôle des autorités religieuses dans la structuration du savoir et $\mathrm{du}$ pouvoir politique en Iran. Elle affronte par la suite la question délicate des définitions du sinemā-ye ma'nāgarā et sinemā-ye rowhānī, c'est à dire d'un cinéma religieux ou de films qui ont trait à la religion ou qui sont habités par une dimension touchant au sacré. Elle étudie ainsi de façon rigoureuse la façon dont ces termes sont employés en persan par des clercs, des responsables culturels et des réalisateurs et l'univers de sens que ces termes recouvrent. Un des points les plus saillants de ce livre réside dans cette analyse critique des définitions données non seulement dans des ouvrages consacrés au sujet, mais aussi lors de manifestations tels que des festivals organisés par des institutions publiques iraniennes.

3 L'A. étudie par la suite très finement les films qui examinent la place de la religion et des autorités religieuses dans la société iranienne post-révolutionnaire, en analysant plus particulièrement Le Lézard de Kamāl Tabrīzī (2004) et Sous le clair de lune de Reḍā Mīrkarīmī (2001). Elle révèle ainsi que ces films, apparemment critiques sur la question, 
restent en fait plus en retraits que des clercs réformateurs et des intellectuels tels que Ḥasan Yūsefĩ Eškevarī, l'āyatollāh Montazereī, Sorūš ou Kadīvar.

4 Nacim Pak-Shiraz termine son étude en se penchant sur la façon dont des figures religieuses, spécifiques au shi'ime (et particulièrement celle de l'Imam Ḥoseyn) ainsi que la forme dramatique du ta'zie, ont donné des cadres narratifs et d'inspiration religieuse à des auteurs majeurs du cinéma iranien comme Majīd Majīīi, Bahrām Beyḍā'ī et 'Abbās Kīārostamī. Elle montre aussi comment leurs films ont été travaillés par la pensée du soufisme, de la philosophie et de la poésie iraniennes.

Si le livre de Nacim Pak-Shiraz permet d'étudier le cinéma iranien contemporain à partir d'un angle délaissé en Occident, la pensée shi'ite reste paradoxalement quelque peu évacuée dans ses aspects les plus réceptifs à la forme cinématographique. Ainsi, la vision duelle du monde, comportant un rapport fort entre ce qui est apparent et ce qui demeure caché (zāher et bātenen), notion si présente dans le shi'isme, n'est quasiment pas évoquée. Le cinéma, art du visible et de l'invisible, semble pourtant particulièrement en phase avec cette notion. Dans cette perspective, le choix revendiqué de mettre à l'écart un réalisateur comme Morteḍā Āvīnī, choix apparemment justifié par des lectures de secondes mains plus que par l'analyse des films du réalisateur, contribue à négliger la mise en rapport du cinéma avec cette notion du shi'isme. Cette prise en compte aurait peut-être permis de mieux comprendre pourquoi le cinéma, dans sa dimension la plus exigeante, a trouvé en Iran un développement si fécond, cherchant à créer chez le spectateur une " initiation du regard ", une construction d'image au-delà de ce qui est immédiatement représenté sur l'écran. C'est moins par le sujet explicite (sur la religion, les religieux...) que par la mise en scène (notamment celle de Kīārostamī voire même de Āvīnī) que ce cinéma touche peut-être le plus singulièrement à une dimension évoquant le sacré. Par ailleurs, en concentrant son étude sur les films de ces vingt dernières années, l'A. tend à se dessaisir de la profondeur historique de la cinématographie iranienne laissant par exemple Sohrāb Šahīd Tāaleț, Dārīūš Mehrjū'î, Nāṣer Taqvā'ì ou encore Parvīz Kīmīāvī en grands absents de cet ouvrage.

Ces regrets ne doivent en aucun cas amoindrir ce riche travail d'enquêtes de terrain ainsi que la qualité d'analyse et d'écriture que possède cet ouvrage qui marquera les études sur le cinéma iranien d'une approche nouvelle et même plus largement les études sur la place de la religion dans la société iranienne contemporaine.

\section{AUTEURS}

\section{AGNÈS DEVICTOR}

Université Panthéon Sorbonne 